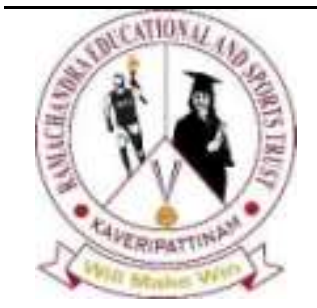

Contemporaneity of Language and Literature in the Robotized Millennium

Vol: 3(1), 2021

REST Publisher

ISBN: 978-81-936097-3-6

Website: http://restpublisher.com/book-series/cllrm/

\title{
Micro Learning and Flipped Classrooms for ESL Learners \\ S. Krishna
}

AMET University Chennai, Tamil Nadu, India.

Email: krishnaakarthikeyan@gmail.com

\begin{abstract}
Micro learning a significant trend in English Language Teaching has gained popularity in teaching English Language for ESL learners by fusing language concepts with technology and web content. This phenomenal methodology in teaching English to ESL Learners focuses on breaking complex units into simple components that enable learners to understand easilyand to acquire more confidence and participation. Micro Learning has been proved to be not only effective but also engaging as students understand grammatical or language components and the LSRW skills through various activities. Using Micro learning in a flipped classroom is an effective way to reach out to students of all categories from slow Learners to advanced Learners. This paper embarks on identifying Micro Learning and Flipped Classrooms as key methods to be combined with ICT as an effective approach to teach ESL Learners.
\end{abstract}

Key words: Micro Learning, Flipped Classrooms, ICT Tools ZGeneration Learners, Outcome based Learning, Learner Autonomy and Teacher autonomy.

English Language Teaching today has experienced a remarkable change presently. The major shift from traditional mode of teaching and learning to the recent Outcome based innovative Teaching and learning recommended by Blooms Taxonomy marks a milestone in ELT as well. A wide array of Learning apps like Google Classroom, Mentimeter, Near pod, Padlet ,and other such teaching aids like u tubes, blogs and vlogs social media plat forms including Facebook, Twitte, Instagram, watts app and telegram are used as teaching aids that facilitate the innovative Mobile Assisted Learning. With all these technological aids and innovative methodologies teachers try to impart knowledge by fusing content with technology in the form of micro bites. The interface between Impressive visuals sound effects and effective pedagogy adopted by the teacher makes Outcome based Learning feasible. Learners are not homogeneous in their interests, aptitude and attitude. They are varied. Many are active Learners while some are mediocre and few are even academically disconnected. The phenomenal aspect of Micro Learning and flipped classes is that it is simple but innovative and caters to all level of learners and anchors them effectively in class participation. On the whole it is interesting, inclusive and productive. As the old saying goes "necessity is the mother of invention" the pandemic has brought in innumerable challenges which have paved way to the finding of multiple innovative teaching and assessment aids untraded by majority of teachers in academia. Unlike a traditional classroom which focuses on teaching the concepts, assigning the homework's and undertaking tests which test the memory of the contents taught micro Learning is immediate in its approach. It not only focuses on teaching the theoretical but on the immediate application of what is taught. The modules in micro learning incorporate theory practice, application and evaluation all at one stretch. Microlearning hence is leveraged towards a self directed learning in flipped classrooms. Consider a flipped classroom where learners are required to view a set of scenarios. They are presented visually with various ideas representing contemporary scenario. They are asked to study the image/ content/ video clipping for few minutes. Learners are then required to engage in problem-solving to choose the appropriate response to the scenarios presented to them. Critical evaluation of the material or teaching content takes place. According to individual discretion responses arise and are expressed in classrooms. Some agree while others refute. Using microlearning in a flipped classroom works well, as learners can watch the scenarios on their mobile gadgets even before the classroom training begins and use the classroom session for a deeper understanding of the content. Teaching materials are most often shared well in advance before the class begins enabling learners to go through and understand the material or content provided. In a traditional Classroom it's the teacher who talks all the time and the students remain passive. In such a scenario communication fails to happen. We as Teachers honestly are not doing enough because of fear of completion of Curriculum and syllabus. A lot of changes have begun in teaching pedagogy but it's a long way to go. Though Covid is an adversity it has given new opportunities to explore new things. We have debunked old traditional methods and replaced many interesting and innovative ones.

Micro Learning Involves

a. Chunk (plan and divide your content content appropriately)

b. Chew(Deliver a ten minute Lecture video/Reading Material) and

c. Check (Conduct a quick formative assessment) 
* Quiz

\section{Classroom Activities Include}

* MCQ, Fill -Up, One word, T/F, Rewrite

* Reading Comprehension

* Reads and answers questions, Note making, Test

* Listening Comprehension

* Listen and answer Questions

* Writing Composition

Paragraph writing/essay/letters/email/precis/notice writing/circular/agenda/minutes/advertisement Speaking Activities Prompts/Dialogues/Role play/Personal Interview/Group Discussions/ Extempore/ Just a Minute

\section{Tasks and Activities in Micro Learning}

Advantage of Task/Activity is that Tasks are activities with a purpose outside learning. In a task based Micro Learning approach students forget that they are learning a language. Tasks are interesting and engaging. Most students are eager to attend English Classes because they feel they are alive. Tasks and activities not only instill interest but also gets rid of their self- consciousness to stand in front of peer group and to express their opinions and observations on a topic. Groups enable them to engage in these activities without inhibitions. For example we can ask them to write about a Travel diary/ a tour plan to kodaikanal or we can ask them to prepare a roadmap/ to give directions to a particular destination using Google Maps. Process to Product A step by step description/ instruction on a process/ a product. Activities include brainstorming/outlining/drafting For example ask students to browse a recent product in amazon/flipkart/any online app and attach the image of a product and describe it in a class as a group Next we can ask them to describe how to prepare a recipe

\section{Proper planning in Micro Learaning involves}

- $\quad$ Target Students( primary, intermediate and advanced)

- Curriculum and syllabus (all classroom activities must fall under curriculum and syllabus)

- Duration of the class ( hours of the course)

- Available resources (black board, white board. Internet, apps, software etc

\section{Types of Activities in Micro learning are}

- Individual (presentations/ seminars/teaching small contents ,JAM, Extempore)

- Pair (Discussions, note making, Games)

- Group( Flash cards, discussions, critical thinking and case studies)

$\bullet$

- Seating arrangements( circle, semicircle)

\section{Micro Learning Class setting}

- $\quad$ Setting up the Tools (Laptop, projector, smart board speakers etc)

- Providing Materials(handouts,

$\bullet$

- Briefing/Instructions

\section{Conducting Activities in Micro Learning involves}

- Clarifying doubts

- Brain storming on contemporary issues

- Debates and discussions

- Directing the students to participate (as many students will hesitate to participate)

- Monitoring

- Loaded with activities

- Windbreaks and recaps

- Teaching content based on Real Life examples /case studies // autobiographies/Biography/Motivational speeches/ TED talks

- Micro teaching and presentations are given importance( students are allotted small topics and asked to handle class/ make a presentation

- Micro writing emphasized; blogs, vlogs, web content, writing developed by writing content in social media like Face book, Instagram, Twitter. E writing, emails, reports, minutes, advertisements, e content, short stories, essays, jokes etc

- Internet as an effective medium 
S. krishna .et.al / Contemporaneity of Language and Literature in the Robotized Millennium 3(1) 2021, 44-46

\begin{tabular}{|l|l|}
\hline TRADITIONAL CLASSROOM & FLIPPED CLASSROOM \\
\hline Focus on Lectures & Focus on Student participation \\
\hline $\begin{array}{l}\text { Materials are prescribed Text books and Lecture } \\
\text { notes }\end{array}$ & $\begin{array}{l}\text { Materials are generated based on innovative topics } \\
\text { handled and taught through Micro Learning } \\
\text { methods }\end{array}$ \\
\hline Students are taught & Students are trained \\
\hline No use of ICT tools & Use of ICT and other resources \\
\hline Learning is route and monotonous & Learning is fun \\
\hline Select students only are active & All students are engaged and active \\
\hline No Teacher autonomy & Teacher Autonomy exercised \\
\hline Sterile (No space for creativity) & Creative (Students create) \\
\hline Correct answers alone are valued & All thinking valued \\
\hline Rigid, closed and controlled environment & Relaxed, open and self controlled environment \\
\hline
\end{tabular}

In order to enable an outcome based learning among students its important to fill the gap between 'knowing' and 'doing'. Let every unit covered contain information supported by student action. The following activities provide hands on experience:
a. Solving problems
b. Real life case studies
c. C. writing short essays/ criticism on a particular event
d. Conversation with peer group
e. Reviewing notes or what they have journaled
f. Answering instructor questions

\section{The Working Mechanics in Micro Learning}

In any Micro Learning module the Students are allocated specific topics/case study/ activity and given 3 to 6 minutes to learn one specific objective by doing one or many of the following
a. Watching a small instructional video and answering the questions
b. Playing online games that aims to teach a specific task
c. Reading summaries and answering a series of questions
d. Viewing infographics and answering questions
e. Using virtual flash cards to prepare for quiz
f. Virtually participating in scenario based situations

Micro Learning is a bite sized spaced Learning that makes course content easy to digest and retains by delivering it in bite sized chunks. Being an educational stratergy that makes complex topics down into short and stand alone units of study that can be viewed as many times as possible. This provides a convenient learning ambience both from the Learner and Instructor point of view and it's the much sought after in corporate learning environments. The instruction modules are designed in such a way that they can be comprehended by the learner in a matter of five minutes and address one specific skill or topic. Sometimes it's a self directed approach in learning that gives opportunity for the learners to develop new skills in course of learning.Neuroscience has proven that for the $\mathrm{z}$ Generation Learners of today the attention span lasts not more than 10 minutes its effective to deliver these micro contents that are easily absorbed and digested. These methods provide students the opportunity to retain and recallinformation therefore committing it to their long term memory by spacing out content. We have to keep their minds engaged by delivering contents in different formats such as videos, voice over slides, audio, text and panel discussions. Micro Learning improves focus and provides long term retention upto 80 percent. Micro Learning materials are generated and accessed based on the need for knowledge development and skill development. It's been proven to be the best approach for the current ZGeneration of learners.

1. M.Kapp, Karl.M “Micro Learning.” Perlego .2019

\section{References}

2. Josseph Rene corbel, Badrul H.Khan and Maria Elena Corbeil. Micro Learning in The Digital Age Ed: Routledge, 2021 